\title{
Periaortic glue application may prevent fatal aortic rupture in nonoperable patients with acute type $A$ aortic dissection
}

Rachid Zegdi, MD, PhD, ${ }^{a, b}$ Brahim Amahzoune, MD, ${ }^{a}$ Paul Achouh, MD, ${ }^{a, b}$ Christian Latrémouille, MD, PhD, a,b Alain Deloche, MD, ${ }^{a, b}$ and Jean-Noël Fabiani, MD, ${ }^{a, b}$ Paris, France

丹 Supplemental material is available online.

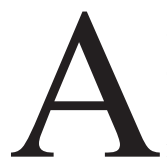

cute type A aortic dissection is a condition requiring emergency surgery. However, surgical intervention is controversial in concomitant stroke. We report a novel approach that prevented fatal aortic rupture in a patient with acute type A dissection with major stroke for whom the surgical cure was intentionally delayed.

\section{Clinical Summary}

A 65-year-old woman was hospitalized for right hemiplegia and aphasia rapidly complicated by a comatose state. Initial evaluation revealed temporal ischemic stroke and acute type A aortic dissection (Figure 1, $A$ and $B$ ). It was decided to delay surgery. Circulatory shock developed owing to cardiac tamponade. It was then decided to evacuate the pericardial effusion through a median sternotomy and try to limit the risk of rupture by external gluing of

From Assistance Publique-Hôpitaux de Paris, Service de Chirurgie CardioVasculaire, Hôpital Européen Georges Pompidou, ${ }^{a}$ Université René Descartes, ${ }^{\mathrm{b}}$ Paris, France.

Received for publication March 8, 2007; revisions received March 27, 2007; accepted for publication April 19, 2007.

Address for reprints: Rachid Zegdi, MD, PhD, Hôpital Européen Georges Pompidou, Service de Chirurgie Cardiovasculaire, 20, rue Leblanc, 75908 Paris, France (E-mail: rzegdi@hotmail.com).

J Thorac Cardiovasc Surg 2007;134:1349-50

$0022-5223 / \$ 32.00$

Copyright @ 2007 by The American Association for Thoracic Surgery doi:10.1016/j.jtcvs.2007.04.070 the aorta. Inspection did not show any active bleeding. Manipulation of the aorta was avoided. Gelatin-resorcine-formaldehyde (GRF) glue was applied externally all around the ascending aorta, so that the intrapericardial segment of the aorta was no longer visible. After placement of chest tubes, the chest was closed and the patient transferred to the intensive care unit.

Neurologic recovery was satisfactory in the following weeks, with complete regression of hemiplegia and partial recovery from aphasia. One week after the initial surgical intervention, a computed tomographic (CT) scan had revealed moderate periaortic hematoma (Figure 2, A). Two weeks later, a suprasternal mass developed. Repeat CT scan showed a large periaortic hematoma extending to the sternum (Figure 2, B). The patient underwent emergency surgery for an aortic false aneurysm. Sternotomy was performed under femoro-femoral bypass and deep hypothermic circulatory arrest. A left anterolateral rupture of the aorta was found. The ascending aorta was replaced with a Dacron graft after resuspension of the three aortic valve commissures.

The postoperative course was uneventful and 3 years after the operation the patient is doing well. No false aortic aneurysm was noted on most recent CT scan (Figure E1).

\section{Discussion}

The management of patients with acute type A aortic dissection and concomitant stroke is still controversial. Although systemic anticoagulation and cerebral reperfusion may aggravate stroke, this risk is poorly defined. ${ }^{1}$ Many surgeons prefer to delay surgery in this clinical setting. ${ }^{2}$ Others still recommend surgery within the first 12 hours from the onset of neurologic deficit, provided no cerebral hemorrhage is documented on preoperative CT scan. ${ }^{3,4}$

In the present case, surgery was delayed owing to aggravation of the neurologic status. When a life-threatening tamponade developed, surgical treatment of the aortic dissection was still considered inappropriate, and external gluing of the aorta was per-
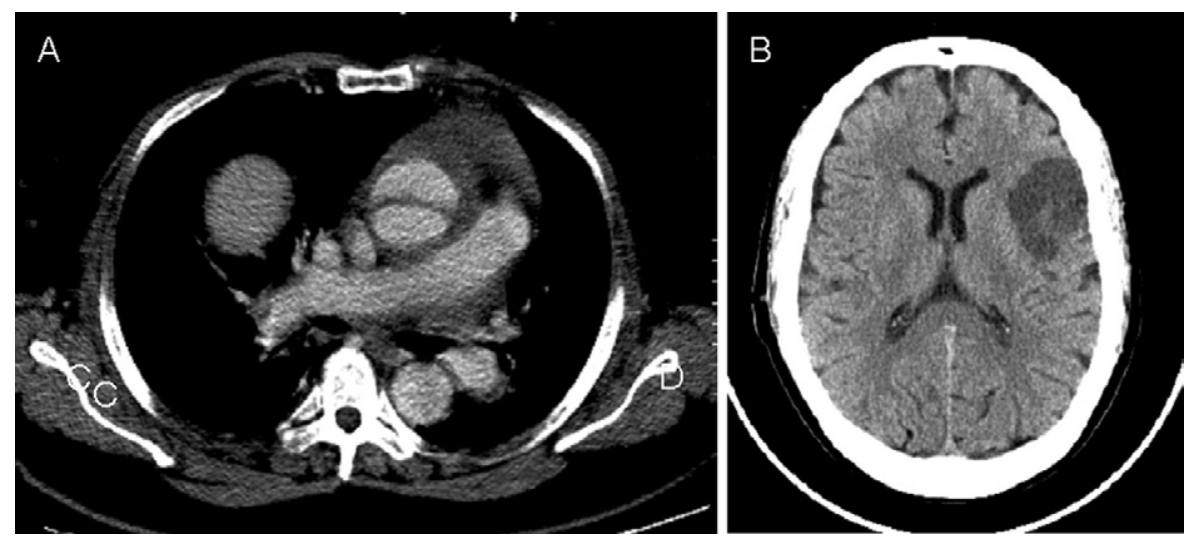

Figure 1. A, Chest CT scan showing type $A$ aortic dissection. $B$, Left temporal ischemic stroke was present on admission. 

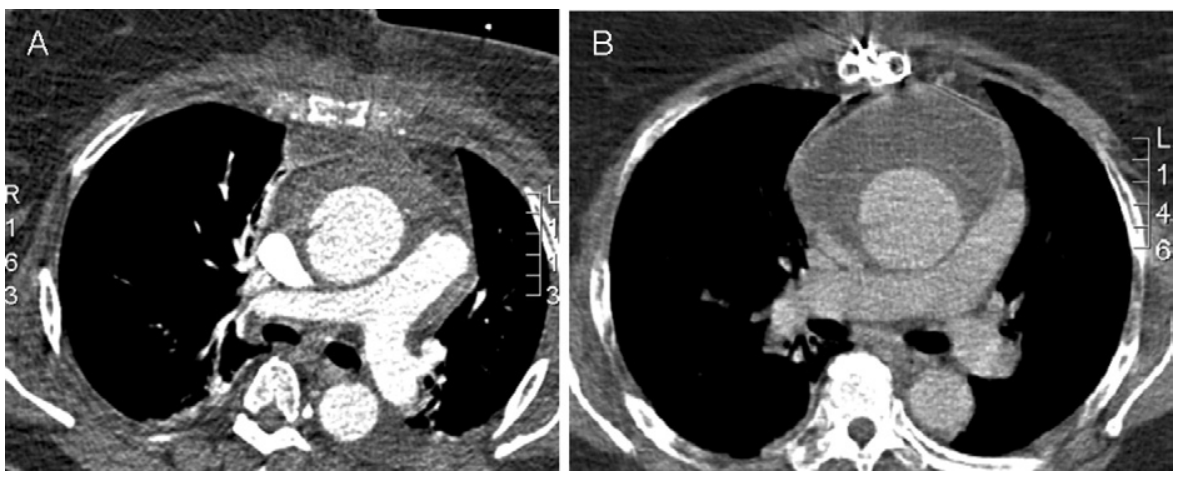

Figure 2. A, Periaortic hematoma 1 week after periaortic GRF gluing. B, Large aortic false aneurysm 3 weeks after initial periaortic gluing.

formed. GRF glue was preferred to other biologic glue because of its "hardening" effect. Gluing was preferred to aortic wrapping (the Robicsek technique) because of less manipulation of the aorta and better "covering" of the noncoronary sinus of Valsalva with the first technique.

Our patient underwent an emergency operation for tamponade with an impending aortic rupture. We cannot rule out with certainty the hypothesis that GRF may have favored such an event. Nevertheless, what is certain is that the application of GRF glue contained the rupture that occurred in the few days after the dissection (as demonstrated by the first postoperative CT scan) and that would have been otherwise fatal for the patient.

This technique may be applied to patients with documented acute type A aortic dissection before transfer to a distant specialized cardiac center, especially when a compressive pericardial effusion is present. It may also be envisioned as a palliative procedure for patients with particularly high operative risk, such as elderly patients. ${ }^{5}$

In conclusion, aortic rupture may be prevented by external GRF gluing. The latter may be indicated in patients with acute type A aortic dissection and temporary (or permanent) contraindication to conventional surgery.

\section{References}

1. Fann JI, Sarris GE, Mitchell RS, Shumway NE, Stinson EB, Oyer PE, et al. Treatment of patients with aortic dissection presenting with peripheral vascular complications. Ann Surg. 1990;212:705-13.

2. Fukuda I, Imazuru T, Tsukuba A. Intentional delay of surgery for acute type A dissection with stroke. J Thorac Cardiovasc Surg. 2003;126:290-1.

3. Pocar M, Passolunghi D, Moneta A, Mattioli R, Donatelli F. Coma might not preclude emergency operation in acute aortic dissection. Ann Thorac Surg. 2006;81:1348-52.

4. Estrera AL, Garami Z, Miller CC, Porat EE, Achouh PE, Dhareshwar J, et al. Acute type A aortic dissection complicated by stroke: can immediate repair be performed safely? J Thorac Cardiovasc Surg. 2006;132: 1404-8.

5. Neri E, Toscano T, Masseti M, Capannini G, Carone E, Tucci E, et al. Operation for acute type A aortic dissection in the octogenarians: is it justified? J Thorac Cardiovasc Surg. 2001;121:259-67. 

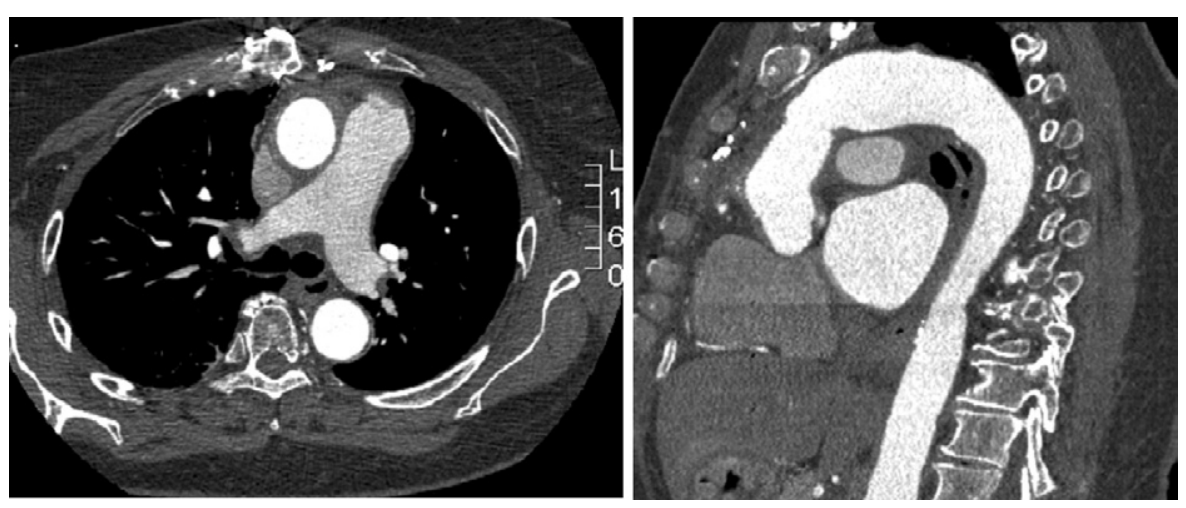

Figure E1. CT scans showing no false aneurysm at 3 years. 